\title{
Regional Variation in Primary Care Involvement at the End of Life
}

Claire K. Ankuda, MD, MPH

Stephen M. Petterson, $P b D^{2}$

Peter Wingrove, $B S^{2}$

Andrew W. Bazemore, MD, MPH

'Robert Wood Johnson Clinical Scholars Program, Family Medicine, University of Michigan Health System, Ann Arbor, Michigan

${ }^{2}$ Robert Graham Center, Washington, DC

\begin{abstract}
PURPOSE Variation in end-of-life care in the United States is frequently driven by the health care system. We assessed the association of primary care physician involvement at the end of life with end-of-life care patterns.

METHODS We analyzed 2010 Medicare Part B claims data for US hospital referral regions (HRRs). The independent variable was the ratio of primary care physicians to specialist visits in the last 6 months of life. Dependent variables included the rate of hospital deaths, hospital and intensive care use in the last 6 months of life, percentage of patients seen by more than 10 physicians, and Medicare spending in the last 2 years of life. Robust linear regression analysis was used to measure the association of primary care physician involvement at the end of life with the outcome variables, adjusting for regional characteristics.
\end{abstract}

RESULTS We assessed 306 HRRs, capturing 1,107,702 Medicare Part B beneficiaries with chronic disease who died. The interquartile range of the HRR ratio of primary care to specialist end-of-life visits was 0.77 to 1.21 . HRRs with high vs low primary care physician involvement at the end of life had significantly different patient, population, and health system characteristics. Adjusting for these differences, HRRs with the greatest primary care physician involvement had lower Medicare spending in the last 2 years of life $(\$ 65,160$ vs $\$ 69,030 ; P=.003)$ and fewer intensive care unit days in the last 6 months of life $(2.90$ vs $4.29 ; P<.001)$, but also less hospice enrollment ( $44.5 \%$ of decedents vs $50.4 \% ; P=.004)$.

CONCLUSIONS Regions with greater primary care physician involvement in endof-life care have overall less intensive end-of-life care.

Ann Fam Med 2017;15:63-67. https://doi.org/10.1370/afm.2002

\section{INTRODUCTION}

$\mathrm{D}$ uring the last decade, individuals dying in the United States have received an increasing volume and intensity of care without clear improvements in the quality of that care. Although rates of hospice enrollment have doubled, levels of intensive care and burdensome care transitions have risen as well. ${ }^{1}$ Intensity of care at the end of life continues to have substantial regional variability ${ }^{2}$ with little relationship to patient preference. ${ }^{3}$ Health system factors such as intensive care unit (ICU) bed density and physician characteristics ${ }^{4-6}$ have been found to be major drivers of end-of-life care intensity. Understanding the potential influence of the primary care physician in this shifting landscape is critical to explaining variations in care patterns and identifying opportunities for quality improvement.

Primary care involvement in coordinating and providing continuity of care improves overall health outcomes. Regions with greater densities of primary care physicians have fewer ambulatory care-sensitive hospitalizations, ${ }^{7,8}$ lower mortality, ${ }^{7}$ and less Medicare spending ${ }^{7}$ for the general Medicare population. Patients with lung cancer whose primary care physicians are involved during their hospitalizations have $25 \%$ lower odds of ICU care. ${ }^{9}$ Patients with more primary care physician visits preceding the last 6 to 12 months of life have been noted to have fewer hospital days, lower 
costs, and lower rates of in-hospital death. ${ }^{10}$ Primary care improves patient care through several mechanisms: coordination of care and services, ${ }^{11,12}$ continuity of relationships ${ }_{1}^{13}$ and comprehensiveness of practice. ${ }^{14}$

Research gaps exist in several aspects of primary care physician participation in end-of-life care. It is debated to what degree primary care physicians are involved in care at this time, as they are perceived as often transferring the care of the dying to specialists, especially for patients with cancer. ${ }^{15-17}$ Studies attempting to measure this, however, have found considerable primary care physician involvement specifically for patients with terminal cancers. ${ }^{17,18}$ The association between primary care physician involvement in end-oflife care and hospice referral is also debated. Some evidence suggests generalists refer to hospice earlier than specialists do, ${ }^{19,20}$ but other studies show the reverse. ${ }^{21}$ Physicians and patients may avoid hospice referral if it means their relationship ends. ${ }^{22}$ Long duration of relationship had been reported to decrease prognostic accuracy, thereby reducing the ability of physicians to identify patients with 6 -month life expectancies. ${ }^{23}$

Given our aging population, understanding and optimizing the role of primary care physicians in care at the end of life is critical to both improve the care of the dying and reduce unnecessary, costly intensive care. We therefore set out to measure and characterize regional variation in primary care physician involvement at the end of life and determine the association of high regional primary care physician involvement with end-of-life outcomes.

\section{METHODS}

\section{Data and Population}

The unit of our analysis was the hospital referral region (HRR), the market area for tertiary care commonly used in analysis of variation across small areas. ${ }^{24} \mathrm{We}$ analyzed 2010 HRR-level data from the Dartmouth Atlas. ${ }^{25}$ The data are derived from 2010 Medicare files for fee-for-service enrollees, including the Denominator files, the MedPAR file, the inpatient file, the physician file (for a $20 \%$ sample of Part B beneficiaries), the Outpatient file (again for a 20\% Part B sample), and the Hospice file. The Medicare cost data are adjusted for regional price difference. A full description of the Dartmouth Atlas data set is given elsewhere in an online compendium of research methods. ${ }^{26}$

We collected data for a cohort of the 2010 Medicare beneficiaries having chronic illness. The cohort was determined to have at least 1 of the following conditions: cancer/leukemia, congestive heart failure, chronic pulmonary disease, dementia, diabetes with end organ damage, peripheral vascular disease, chronic renal failure, severe chronic liver disease, and coronary artery disease.

\section{Independent Measures}

The primary independent variable was the ratio of primary care visits to specialist visits in the last 6 months of life, calculated from Medicare claims data of visits billed over this time period. Primary care physicians were defined as family practice or internal medicine physicians. On the basis of evidence suggesting that primary care physician coordination is overwhelmed if patients are also seeing a large number of specialists, ${ }^{11}$ we used the ratio of primary care physician to specialist visits instead of the absolute number or frequency of primary care physician visits. This ratio has been established as a marker of the orientation of the health care system toward primary care, ${ }^{27}$ which is especially suitable for our study of regional characteristics.

Covariates included HRR-level demographic information from the Medicare files such as age, sex, race, and the mean hierarchical condition category score, which is a count of conditions intended to estimate degree of illness. Given evidence that population health measures improve over counts of chronic conditions in adjusting for regional illness levels, ${ }^{28}$ we collected HRR-specific obesity and smoking rates from the 2010 Behavioral Risk Factor Surveillance System. We used the 2010 AMA Masterfile to capture regional physician densities. Zip code-level Rural-Urban Commuting Area codes (RUCAs) were used along with census data to calculate the percent of each HRR defined as urban (RUCA <4).

\section{Outcome Measures}

Primary outcome measures were the percent of deaths occurring in the hospital, aggregate hospice enrollment rates, percent of patients seeing 10 or more physicians in the last 6 months of life, percent of patients receiving ICU care during their final hospital admission, hospital and ICU days in the last 6 months, and Medicare spending. These measures are commonly reported population-level indicators of end-of-life care. ${ }^{1,29,30}$

\section{Analysis}

We divided the 306 HRRs evenly into quartiles based on the ratio of primary care to specialist involvement at the end of life. Patient, population, and workforce characteristics were described for each quartile. To measure the association between each characteristic and primary care involvement at the end of life, we used robust linear regression analysis. Robust methods were used for all analyses to reduce the influence of any outliers or heteroscedasticity that could bias the model. The independent variable in this model was the 
HRR-level ratio of primary care to specialist visits, not the quartile of HRRs.

Robust linear regression analysis was then used to measure the association of primary care-to-specialist ratio with end-of-life care patterns, with each end-of-life care variable as the dependent variable, and the ratio of visits as the primary independent variable. Covariates in these models include the percentage of the HRR below $100 \%$ of the Federal Poverty Limit (FPL), percentage of African American beneficiaries, mean beneficiary age, percentage of female beneficiaries, average Hierarchical Condition Category (HCC) score, percentage of beneficiaries living in an urban zip code, regional obesity rates, stroke rates, and density of specialist physicians. We selected these variables a priori and then tested them for multicollinearity. In addition, the models were tested for normal residuals and influential outliers. From these models, we determined the $P$ value of associa-

tion between primary care involvement and end-of-life outcomes from a regression analysis using the HRR-level primary care-to-specialist ratio. The models were then used to predict the level of each end-oflife care variable, adjusted by all covariates, for each quartile of HRRs ranked by primary care involvement.

All analysis was done using STATA version 13.1 statistical software (StataCorp LP). Institutional review board approval was not sought, as the data for this study were entirely publicly available, non-individual level data.

\section{RESULTS}

We assessed 306 HRRs, in which a total of 1,107,702 Medicare Part B beneficiaries with chronic disease died in 2010. There was great variation in the regional ratio of primary care physician to specialist visits in the last 6 months of life, with a mean of 0.98 and an interquartile range of 0.77 to 1.21 (Table 1 ).

HRRs with more primary care physician involvement at the end of life were significantly different from those with less primary care physician involve- ment in nearly every characteristic (Table 1). Quartiles with greater primary care physician involvement at the end of life had different demographics than those with less primary care physician involvement at the end of life, with fewer African Americans, smaller percentages of urban-dwelling individuals, and lower mean HCC scores. Although the density of physicians was similar across quartiles, the quartile with the most primary care physician involvement at the end of life had a different composition of physicians, with more primary care physicians and fewer specialists, as well as fewer ICU beds.

Significant variation by primary care involvement was seen in the end-of-life outcomes of interest, even after adjusting for patient characteristics, population characteristics, and specialist density (Table 2). Regions in the highest quartile of primary care physician involvement had lower hospice enrollment rates compared with those in the lowest quartile $(44.5 \%$ vs $50.4 \%, P=.004)$, but less ICU care (2.90 vs 4.29 days
Table 1. Characteristics of Hospital Referral Regions by Quartile of Mean Ratio of Primary Care to Specialist Visits in the Last 6 Months of Life

\begin{tabular}{|c|c|c|c|c|c|}
\hline \multirow[b]{2}{*}{ Measure } & \multicolumn{4}{|c|}{ Quartile of PCP Involvement } & \multirow[b]{2}{*}{$\begin{array}{c}P \\
\text { Value }\end{array}$} \\
\hline & $\begin{array}{c}\begin{array}{c}\text { First } \\
\text { (Lowest) } \\
(n=76)\end{array}\end{array}$ & $\begin{array}{l}\text { Second } \\
(\mathrm{n}=77)\end{array}$ & $\begin{array}{l}\text { Third } \\
(\mathrm{n}=77)\end{array}$ & $\begin{array}{l}\text { Fourth } \\
\text { (Highest) } \\
(\mathrm{n}=76)\end{array}$ & \\
\hline \multicolumn{6}{|l|}{ Outcomes } \\
\hline $\begin{array}{l}\text { Deaths of chronically ill } \\
\text { beneficiaries, No. }\end{array}$ & 376,118 & 303,772 & 242,084 & 185,728 & - \\
\hline $\begin{array}{l}\text { Ratio of PCP:specialist } \\
\text { visits in the last } 6 \text { mo } \\
\text { of life (range) }\end{array}$ & $\begin{array}{c}0.66 \\
(0.38-0.77)\end{array}$ & $\begin{array}{c}0.88 \\
(0.78-0.98)\end{array}$ & $\begin{array}{c}1.08 \\
(0.98-1.21)\end{array}$ & $\begin{array}{c}1.42 \\
(1.21-2.55)\end{array}$ & - \\
\hline \multicolumn{6}{|l|}{ Patient characteristics } \\
\hline Mean age, y & 72.11 & 71.31 & 70.97 & 71.08 & $<.001$ \\
\hline Female, \% & 56.0 & 55.5 & 55.2 & 54.3 & $<.001$ \\
\hline African American, \% & 11.4 & 10.2 & 7.9 & 3.6 & $<.001$ \\
\hline HCC score, mean & 1.04 & 0.99 & 0.97 & 0.92 & $<.001$ \\
\hline \multicolumn{6}{|l|}{ Population characteristics } \\
\hline Below FPL, \% & 13.9 & 16.1 & 15.9 & 15.5 & .005 \\
\hline Urban, \% & 92.8 & 79.1 & 68.3 & 55.1 & $<.001$ \\
\hline Obese, \% & 25.2 & 27.5 & 27.3 & 27.4 & $<.001$ \\
\hline History of stroke, \% & 4.5 & 3.9 & 3.8 & 3.3 & $<.001$ \\
\hline \multicolumn{6}{|l|}{$\begin{array}{l}\text { Health care supply } \\
\text { characteristics }\end{array}$} \\
\hline $\begin{array}{l}\text { Medical doctors per } \\
\text { 100,000, No. }\end{array}$ & 203.23 & 187.50 & 188.70 & 192.90 & .10 \\
\hline PCPs per 100,000, No. & 51.10 & 49.57 & 56.42 & 63.18 & $<.001$ \\
\hline $\begin{array}{l}\text { Specialists per 100,000, } \\
\text { No. }\end{array}$ & 130.23 & 118.59 & 116.60 & 114.96 & $<.001$ \\
\hline $\begin{array}{l}\text { Hospital beds per } \\
\text { 1,000, No. }\end{array}$ & 50.74 & 43.23 & 41.05 & 37.67 & $<.001$ \\
\hline $\begin{array}{l}\text { ICU beds per 1,000, } \\
\text { No. }\end{array}$ & 21.49 & 15.95 & 12.24 & 10.24 & $<.001$ \\
\hline \multicolumn{6}{|c|}{$\begin{array}{l}\mathrm{FPL}=\text { federal poverty limit; } \mathrm{HCC}=\text { hierarchical condition category; } \mathrm{HRR}=\text { hospital referral region; } \mathrm{ICU}=\text { intensive } \\
\text { care unit; } \mathrm{PCP}=\text { primary care physician. }\end{array}$} \\
\hline \multicolumn{6}{|c|}{ Note: There were 306 HRRs, capturing 1,107,702 total decedents in 2010 . } \\
\hline \multicolumn{6}{|c|}{ a Chronically ill Medicare beneficiaries, deceased in 2010.} \\
\hline
\end{tabular}


Table 2. End-of-Life Care in HRRs by Quartile of Primary Care Involvement in the Last 6 Months of Life

\begin{tabular}{|c|c|c|c|c|c|}
\hline \multirow[b]{2}{*}{ Measure } & \multicolumn{4}{|c|}{$\begin{array}{l}\text { Quartile of HRRs by Ratio of Primary Care to } \\
\text { Specialist Visits in the Last } 6 \text { Months of Life }\end{array}$} & \multirow[b]{2}{*}{$\begin{array}{c}P \\
\text { Value }^{a}\end{array}$} \\
\hline & $\begin{array}{c}\text { First (Least } \\
\text { PCP Involvement) } \\
(\mathrm{n}=76)\end{array}$ & $\begin{array}{l}\text { Second } \\
(n=76)\end{array}$ & $\begin{array}{l}\text { Third } \\
(n=76)\end{array}$ & $\begin{array}{c}\text { Fourth (Most } \\
\text { PCP Involvement) } \\
(\mathrm{n}=77)\end{array}$ & \\
\hline Deaths occurring in hospitals, \% $(95 \% \mathrm{Cl})$ & $\begin{array}{c}24.5 \\
(23.8-25.1)\end{array}$ & $\begin{array}{c}24.0 \\
(23.5-24.5)\end{array}$ & $\begin{array}{c}24.0 \\
(23.5-24.5)\end{array}$ & $\begin{array}{c}24.0 \\
(23.4-24.6)\end{array}$ & .55 \\
\hline Decedents enrolled in hospice, \% (95\% Cl) & $\begin{array}{c}50.4 \\
(49.1-51.7)\end{array}$ & $\begin{array}{c}48.1 \\
(47.2-49.1)\end{array}$ & $\begin{array}{c}47.9 \\
(46.9-48.9)\end{array}$ & $\begin{array}{c}44.5 \\
(43.3-45.7)\end{array}$ & .004 \\
\hline $\begin{array}{l}\text { Patients seeing } \geq 10 \text { physicians in their last } \\
6 \text { mo of life, } \%(95 \% \mathrm{Cl})\end{array}$ & $\begin{array}{c}42.4 \\
(41.6-43.1)\end{array}$ & $\begin{array}{c}37.8 \\
(37.2-38.4)\end{array}$ & $\begin{array}{c}36.9 \\
(36.3-37.6)\end{array}$ & $\begin{array}{l}37.0 \\
(36.3-37.8)\end{array}$ & $<.001$ \\
\hline $\begin{array}{l}\text { Patients receiving ICU care during their final } \\
\text { hospital admission, } \%(95 \% \mathrm{Cl})\end{array}$ & $\begin{array}{c}17.5 \\
(17.0-17.9)\end{array}$ & $\begin{array}{c}15.9 \\
(15.5-16.2)\end{array}$ & $\begin{array}{c}15.2 \\
(14.9-15.6)\end{array}$ & $\begin{array}{c}14.5 \\
(14.1-14.9)\end{array}$ & $<.001$ \\
\hline $\begin{array}{l}\text { Hospital days in the last } 6 \text { mo of life, } \\
\text { No. }(95 \% \mathrm{Cl})\end{array}$ & $\begin{array}{c}9.76 \\
(9.57-9.96)\end{array}$ & $\begin{array}{c}9.10 \\
(8.95-9.25)\end{array}$ & $\begin{array}{c}9.00 \\
(8.84-9.15)\end{array}$ & $\begin{array}{c}9.15 \\
(8.97-9.33)\end{array}$ & .10 \\
\hline ICU days in the last 6 mo of life, No. $(95 \% \mathrm{Cl})$ & $\begin{array}{c}4.29 \\
(4.13-4.44)\end{array}$ & $\begin{array}{c}3.63 \\
(3.51-3.75)\end{array}$ & $\begin{array}{l}3.07 \\
(2.95-3.20)\end{array}$ & $\begin{array}{l}2.90 \\
(2.76-3.05)\end{array}$ & $<.001$ \\
\hline $\begin{array}{l}\text { Total Medicare spending per decedent in last } \\
2 \text { y of life, US } \$ 1,000^{\mathrm{b}}\end{array}$ & $\begin{array}{c}69.03 \\
(68.08-69.98)\end{array}$ & $\begin{array}{c}66.70 \\
(65.96-67.44)\end{array}$ & $\begin{array}{c}64.07 \\
(63.32-64.83)\end{array}$ & $\begin{array}{c}65.16 \\
(64.27-66.05)\end{array}$ & .003 \\
\hline
\end{tabular}

$\mathrm{HRR}=$ hospital referral region; $\mathrm{ICU}=$ intensive care unit; $\mathrm{PCP}=$ primary care physician.

Note: Adjusted for the HRR percentage of population below the federal poverty limit, percentage of Medicare beneficiaries reporting they were African American, percentage of beneficiaries who were female, average age of Medicare beneficiaries, average hierarchical condition category score of Medicare beneficiaries, percentage of HRR that is urban, obesity rate, stroke rate, and regional density of specialist physicians.

a Testing the ratio of primary care to specialist visits as a continuous variable as opposed to quartiles of the ratio.

b In 2010 dollars.

in the ICU in the last 6 months, $P<.001$, and $14.5 \%$ vs $17.5 \%$ of terminal admissions containing ICU care, $P<.001)$. In addition, there was overall less Medicare spending in the last 2 years of life in regions with more primary care physician involvement $(\$ 65,160$ vs $\$ 69,030, P=.003)$ and less fragmentation of care $(37.0 \%$ of decedents saw $\geq 10$ physicians in the last 6 months of life vs $42.4 \%, P<.001)$. There was no difference in hospital deaths or hospital days in the last 6 months.

\section{DISCUSSION}

These findings add evidence to our increasing understanding that physician and health system characteristics often drive variation in end-of-life care. We found notable variation in the involvement of primary care physicians vs specialists in the last months of life. Chronically ill adults living in regions with greater primary care physician involvement experience less hospital and ICU care in their last 6 months of life and are less likely to have more than 10 physicians involved in their care. In addition, these regions have less costly end-of-life care, despite lower rates of hospice use.

Primary care clinicians have previously been shown to improve the quality of care and lower costs of care. There has been little work done, however, on their role in end-of-life care. This study fills in gaps by demonstrating that primary care physicians are the main physicians for about half of the HRRs in the country, and regions where they are the predominant clinician in the last 6 months of life have less costly and intensive end-of-life care.

The finding that greater primary care physician involvement is associated with less hospice use is a paradox worthy of further investigation, with several possible explanations. Primary care physicians may hesitate to refer to hospice if doing so is perceived as terminating a long-standing relationship. ${ }^{22}$ Alternatively, primary care physicians may not recognize patients as having a prognosis of less than 6 months because of their longstanding relationship. ${ }^{23}$ Finally, hospice growth may be concentrated in regions where primary care physicians are not as predominant a source of care. ${ }^{31}$

The results of this study must be interpreted in light of the limitations of its design as a small-area regional analysis. To avoid ecological fallacy, we can make inferences only about regional differences, not about individual associations within regions. Future work needs to examine the extent and impact of primary care involvement on care at the end of life at the patient level. In addition, we used a rough, though validated, measure of primary care involvement: the ratio of primary care physician to specialist visits. We therefore could not capture instances where a single visit to a primary care physician altered the course of treatment, measure unbilled primary care physician coordination of care, or qualify the nature of primary care physician involvement around coordination, advance care planning, 
and discussions about goals of care. A mixed-methods approach will be needed to appreciate the role of primary care physicians in a more nuanced way.

This study provides preliminary evidence that the involvement of primary care physicians is a source of regional variation in end-of-life care. In addition, it is promising that areas of high primary care physician involvement appear to have lower-intensity, lower-cost care. Given the size of the aging population and the magnitude of the primary care physician infrastructure, further work to understand and optimize the role of primary care physicians will be critical to improve care of the dying.

\section{To read or post commentaries in response to this article, see it} online at http://www.annfammed.org/content/15/1/63.

Key words: palliative care; end-of-life care; primary care; healthcare services research; hospice; death; family practice; internal medicine

Submitted August 7, 2015; submitted, revised, July 18, 2016; accepted August 1, 2016.

Funding support: This study was supported by the Robert Graham Center Visiting Scholars Program.

Previous presentations: Findings were previously presented at the North American Primary Care Research Group (NAPCRG) Annual Meeting; October 24-28, 2015; Cancun, Mexico.

\section{References}

1. Teno JM, Gozalo PL, Bynum JP, et al. Change in end-of-life care for Medicare beneficiaries: site of death, place of care, and health care transitions in 2000, 2005, and 2009. JAMA. 2013;309(5):470-477.

2. Goodman DC, Esty A, Fisher E, Chang C. Trends and Variation in Endof-Life Care for Medicare Beneficiaries with Severe Chronic Illness. The Dartmouth Institute for Health Policy and Clinical Practice. http://www. dartmouthatlas.org/downloads/reports/EOL_Trend_Report_0411. pdf. Published Apr 12, 2011.

3. Barnato $A E$, Herndon $M B$, Anthony $D L$, et al. Are regional variations in end-of-life care intensity explained by patient preferences? A study of the US Medicare Population. Med Care. 2007;45(5):386-393.

4. Obermeyer Z, Powers BW, Makar M, Keating NL, Cutler DM. Physician characteristics strongly predict patient enrollment in hospice. Health Aff (Millwood). 2015;34(6):993-1000.

5. Kwok AC, Semel ME, Lipsitz SR, et al. The intensity and variation of surgical care at the end of life: a retrospective cohort study. Lancet. 2011;378(9800):1408-1413.

6. Tschirhart EC, Du Q, Kelley AS. Factors influencing the use of intensive procedures at the end of life. J Am Geriatr Soc. 2014;62(11): 2088-2094.

7. Chang $\mathrm{CH}$, Stukel TA, Flood AB, Goodman DC. Primary care physician workforce and Medicare beneficiaries' health outcomes. JAMA. 2011;305(20):2096-2104.

8. Nyweide DJ, Anthony DL, Bynum JP, et al. Continuity of care and the risk of preventable hospitalization in older adults. JAMA Intern Med. 2013;173(20):1879-1885.

9. Sharma G, Freeman J, Zhang D, Goodwin JS. Continuity of care and intensive care unit use at the end of life. Arch Intern Med. 2009; 169(1):81-86.

10. Kronman AC, Ash AS, Freund KM, Hanchate A, Emanuel EJ. Can primary care visits reduce hospital utilization among Medicare beneficiaries at the end of life? J Gen Intern Med. 2008;23(9):1330-1335.
11. Liss DT, Chubak J, Anderson ML, Saunders KW, Tuzzio L, Reid RJ. Patient-reported care coordination: associations with primary care continuity and specialty care use. Ann Fam Med. 2011;9(4):323-329.

12. Arend J, Tsang-Quinn J, Levine C, Thomas D. The patient-centered medical home: history, components, and review of the evidence. Mt Sinai J Med. 2012;79(4):433-450.

13. De Maeseneer JM, De Prins L, Gosset C, Heyerick J. Provider continuity in family medicine: does it make a difference for total health care costs? Ann Fam Med. 2003;1(3):144-148.

14. Bazemore A, Petterson S, Peterson LE, Phillips RL Jr. More comprehensive care among family physicians is associated with lower costs and fewer hospitalizations. Ann Fam Med. 2015;13(3):206-213.

15. Back AL, Young JP, McCown E, et al. Abandonment at the end of life from patient, caregiver, nurse, and physician perspectives: loss of continuity and lack of closure. Arch Intern Med. 2010;169(5): 474-479.

16. Silveira MJ, Kim SY, Langa KM. Advance directives and outcomes of surrogate decision making before death. N Engl J Med. 2010; 362(13):1211-1218.

17. Dobie S, Saver BG, Wang CY, Green PK, Baldwin LM. Do primary care physicians lose contact with their colorectal cancer patients? J Am Board Fam Med. 2011;24(6):704-709.

18. Klabunde CN, Ambs A, Keating NL, et al. The role of primary care physicians in cancer care. J Gen Intern Med. 2009;24(9):1029-1036.

19. Stillman MJ, Syrjala KL. Differences in physician access patterns to hospice care. J Pain Symptom Manage. 1999;17(3):157-163.

20. Lamont EB, Christakis NA. Physician factors in the timing of cancer patient referral to hospice palliative care. Cancer. 2002;94(10): 2733-2737.

21. Keating NL, Herrinton LJ, Zaslavsky AM, Liu L, Ayanian JZ. Variations in hospice use among cancer patients. J Natl Cancer Inst. 2006; 98(15):1053-1059.

22. Vig EK, Starks H, Taylor JS, Hopley EK, Fryer-Edwards K. Why don't patients enroll in hospice? Can we do anything about it? J Gen Intern Med. 2010;25(10):1009-1019.

23. Christakis NA, Lamont EB. Extent and determinants of error in physicians' prognoses in terminally ill patients: prospective cohort study. West J Med. 2000;172(5):310-313.

24. Wennberg JE, Gittelsohn A. Small area variations in health care delivery. Science. 1973;182(4117):1102-1108.

25. Dartmouth Atlas of Health Care. Downloads on care of chronically ill patients during the last two years of life. The Dartmouth Institute for Health Policy and Clinical Practice. http://www.dartmouthatlas. org/tools/downloads.aspx?tab $=40$. Published 2010 .

26. The Dartmouth Atlas of Health Care. Research methods. http://www. dartmouthatlas.org/downloads/methods/research_methods.pdf.

27. Friedberg MW, Hussey PS, Schneider EC. Primary care: a critical review of the evidence on quality and costs of health care. Health Aff (Millwood). 2010;29(5):766-772.

28. Wennberg DE, Sharp SM, Bevan G, Skinner JS, Gottlieb DJ, Wennberg JE. A population health approach to reducing observational intensity bias in health risk adjustment: cross sectional analysis of insurance claims. BMJ. 2014;348(April):g2392.

29. Morden NE, Fisher ES, Wennberg JE, Bronner EKK. Trends in Cancer Care Near the End of Life: A Dartmouth Atlas of Health Care Brief. http: //www.dartmouthatlas.org/downloads/reports/Cancer_brief_090413. pdf. Published 2013.

30. The Dartmouth Atlas of Health Care. End of life care. http://www. dartmouthatlas.org/data/topic/all.aspx.

31. Thompson JW, Carlson MD, Bradley EH. US hospice industry experienced considerable turbulence from changes in ownership, growth, and shift to for-profit status. Health Aff (Millwood). 2012; 31(6):1286-1293. 